\title{
Non-aqueous cross hydrolysis: an epoxide-free sol-gel route toward highly porous alumina monoliths
}

\author{
Simon Carstens $\mathbb{D}^{1} \cdot$ Igor Atanasov $^{1} \cdot$ Tim Jähnichen $^{1} \cdot$ Bastian Oberleiter $^{2} \cdot$ Dirk Enke $^{1}$
}

Received: 5 May 2021 / Accepted: 13 July 2021 / Published online: 11 August 2021

(c) The Author(s) 2021

\section{Abstract}

Highly porous alumina monoliths can be fabricated by simultaneous hydrolysis of aluminum alkoxides and salts as homonuclear precursors. The use of carcinogenic epoxides can thus be avoided. In this novel approach, no water is added to the system but hydrolysis is induced by the crystal water of the aluminum salt. Mechanical stabilization and significantly increased porosity values can be achieved when the sol-gel synthesis is performed in an autoclave.

\section{Graphical Abstract}

Highly porous, mechanically stable alumina monoliths via a novel epoxide-free sol-gel approach named Cross Hydrolysis

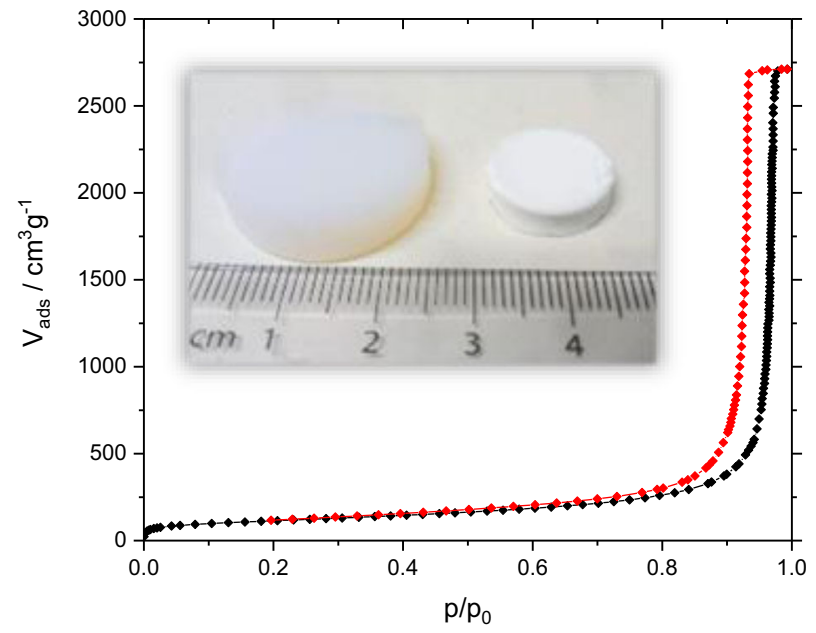

Keywords Alumina monoliths $\cdot$ Alumina xerogel $\cdot$ Evaporative drying $\cdot$ High surface area

Supplementary information The online version contains supplementary material available at https://doi.org/10.1007/s10971021-05595-x

Simon Carstens

simon.carstens@uni-leipzig.de

1 Institute of Chemical Technology, Universität Leipzig, Linnéstr. 3,
D-04103 Leipzig, Germany

2 HEGLA boraident GmbH \& Co. KG, Köthener Straße 33a, D-06118 Halle (Saale), Germany 


\section{Highlights}

- Synthesis of highly porous mechanically stable alumina monoliths.

- Simultaneous hydrolysis of aluminum alkoxide and salt as homonuclear precursors.

- Reaction takes place without an aqueous phase.

There are two different approaches in the sol-gel synthesis of porous alumina. Yoldas was the first to publish an approach using aluminum alkoxides as precursors in 1975 [1]. A patent from the University of Florida (1989) then used an aluminum salt as a peptizing agent for the alkoxidebased gel, yielding stable but non-porous alumina monoliths [2].

With less reactive aluminum salts, an epoxide-mediated route was later suggested by Gash and Baumann [3, 4]. Their approach has since been adapted and further developed by several groups [5-9].

Although this synthesis based on an aluminum salt was developed more than a decade later, the aforementioned patent [2] may be considered a combination of the Yoldas process [1] and the epoxide-mediated synthesis [3, 4]. This approach was further studied by the groups of Dressler and Nofz $[10,11]$. When regarded as starting from the aluminum salt, this process may also be described as the replacement of the carcinogenic epoxide by an aluminum alkoxide. As the cited works all operate in an aqueous medium, this inspired our attempt to omit the aqueous phase, and further extend this combined alumina sol-gel route to the fabrication of highly porous monoliths.

In our approach, the synthesis takes place in a polar but non-aqueous medium, i.e., no water is added to the reaction solution. Hydrolysis of the alkoxide is hence only induced by the crystal water of the aluminum salt, while the alkoxide simultaneously takes on the role of a proton scavenger. Both precursors hence mutually hydrolyze each other in a concerted reaction. We name this novel process cross hydrolysis.

Upon dissolution, the aluminum salt dissociates into solvated anions and aluminum-hexaaqua-complexes [Al $\left.\left(\mathrm{H}_{2} \mathrm{O}\right)_{6}\right]^{3+}$, due to the presence of crystal water in the salt. These hexaaqua-complexes are in equilibrium with the deprotonated form, rendering the medium acidic, as Eq. 1 in Fig. 1 shows. However, the recombination of two pentaaqua-hydroxo-complexes into a dimer does not occur voluntarily. Instead of the commonly used carcinogenic epoxide, an aluminum alkoxide is now employed. Complete hydrolysis of the alkoxide occurs immediately through a nucleophilic substitution of the OR-groups by excess crystal water from the salt precursor (Eq. 2 and 3). As the salt precursor solution is strongly acidic ( $\mathrm{pH} 0.5)$, the colloidal $\mathrm{Al}(\mathrm{OH})_{3}$ is rapidly redissolved and peptized to form an alumina sol (Eq. 4), according to the Yoldas process [1]. Subsequently, hydrolytic olation between the sol particles, which may contain only a few aluminum ions, and the aluminum-aquohydroxo-complexes now takes place. These primary particles interconnect to eventually yield an alumina network structure as depicted in the SEM images in Fig. 2.

With regard to the specific experimental procedure, equal masses of aluminum-tri-sec-butoxide $\mathrm{Al}\left(\mathrm{OC}_{4} \mathrm{H}_{9}\right)_{3}$ and aluminum nitrate nonahydrate $\mathrm{Al}\left(\mathrm{NO}_{3}\right)_{3} \cdot 9 \mathrm{H}_{2} \mathrm{O}$, corresponding to a molar ratio of 3:2, were dissolved in equal amounts of ethanol and 2-propanol. The sol-gel synthesis was then performed in an autoclave at $100^{\circ} \mathrm{C}$ for $24 \mathrm{~h}$, yielding an intact cylindrical lyogel. This is transformed into a mechanically stable monolithic xerogel after drying via a twofold solvent exchange with acetone and pentane. Both solvents exhibit high vapor pressures of $33.0 \mathrm{kPa}$ and $73.5 \mathrm{kPa}$, respectively, at $300 \mathrm{~K}$, which significantly reduces capillary stress within the pores during the drying process ${ }^{1}$.

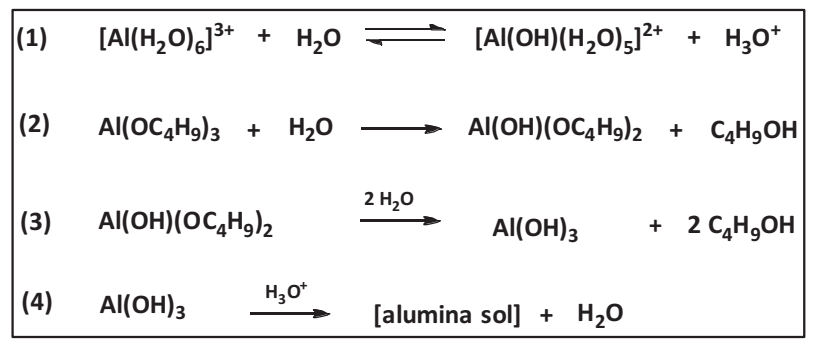

Fig. 1 Scheme of postulated reactions taking place in the solution to form dimeric aluminum-aquo-hydroxo-complexes from both precursors

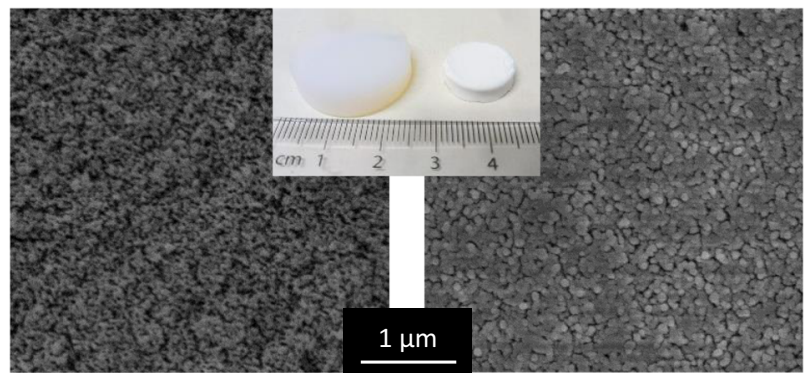

Fig. 2 SEM images and inserted photographs of porous alumina monoliths synthesized via cross hydrolysis of aluminum nitrate and aluminum-tri-sec-butoxide. Calcination temperatures were $600{ }^{\circ} \mathrm{C}$ (left), and $1200{ }^{\circ} \mathrm{C}$ (right), respectively

\footnotetext{
1 The solvents hitherto employed in the drying process, ethanol and 2propanol, exhibit vapor pressures of only 9.1 or $6.5 \mathrm{kPa}$, respectively, at $300 \mathrm{~K}$.
} 


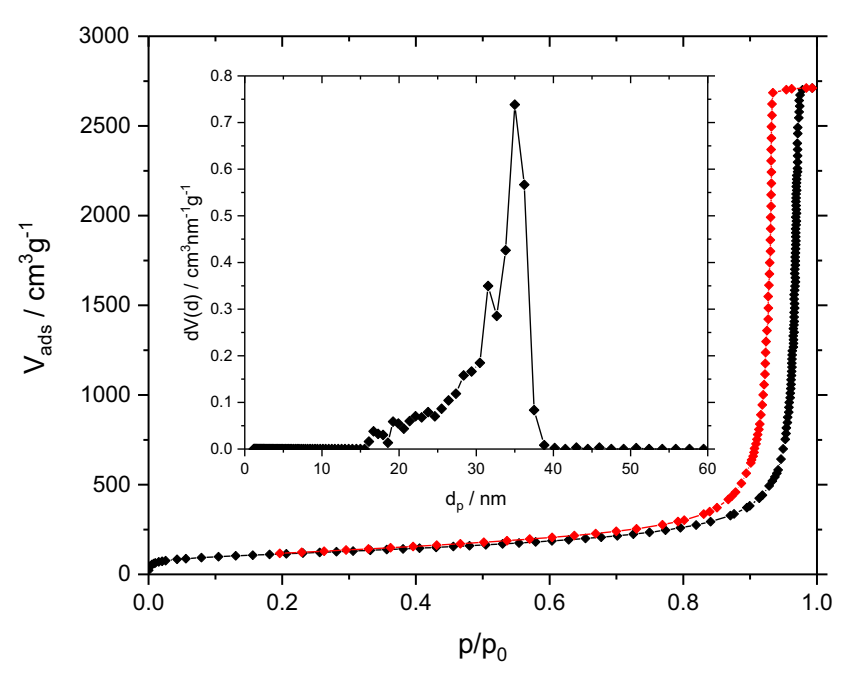

Fig. $3 \mathrm{~N}_{2}$ sorption isotherms of a $\gamma-\mathrm{Al}_{2} \mathrm{O}_{3}$ monolith calcined at $600{ }^{\circ} \mathrm{C}$ for $6 \mathrm{~h}$ (adsorption in black, desorption branch in red). The inset shows the differential pore width distribution with a modal pore diameter of $35.0 \mathrm{~nm}$, calculated from the adsorption branch with the DFT method

Upon calcination at $600{ }^{\circ} \mathrm{C}$, the dimensions of the cylindrical monoliths were $10 \mathrm{~mm}$ in height and $25 \mathrm{~mm}$ in diameter, whereas calcination at $1200{ }^{\circ} \mathrm{C}$ reduces these values to $6 \mathrm{~mm}$ and $15 \mathrm{~mm}$, respectively. Phase evaluation by XRD revealed moderately crystalline $\gamma-\mathrm{Al}_{2} \mathrm{O}_{3}$ for the samples calcined at $600^{\circ} \mathrm{C}$, and pure $\alpha-\mathrm{Al}_{2} \mathrm{O}_{3}$ for those calcined at $1200{ }^{\circ} \mathrm{C}$. Both results are in accordance with the expected phase compositions ${ }^{2}$ [12].

Microstructural characterization of the $\gamma-\mathrm{Al}_{2} \mathrm{O}_{3}$ and $\alpha$ $\mathrm{Al}_{2} \mathrm{O}_{3}$ monoliths was performed by mercury intrusion, nitrogen sorption, and SEM imaging ${ }^{3}$. The $\gamma-\mathrm{Al}_{2} \mathrm{O}_{3}$ monolith exhibits a pore volume of $4.17 \mathrm{~cm}^{3} / \mathrm{g}$, calculated from the $\mathrm{N}_{2}$ sorption measurement. The corresponding type IVa isotherm in Fig. 3 exhibits an almost perfect H1 hysteresis loop, indicating a mesoporous material with a narrow pore width distribution. A modal pore diameter of $35.0 \mathrm{~nm}$ was determined using the DFT method, as shown in the inlay in Fig. 3.

Due to the completed $\alpha$-transition at $1200{ }^{\circ} \mathrm{C}$, the porosity decreases, resulting in a pore volume of $0.44 \mathrm{~cm}^{3} / \mathrm{g}$ for the $\alpha$ $\mathrm{Al}_{2} \mathrm{O}_{3}$ monolith. The pore diameter is shifted to $165 \mathrm{~nm}$. Both values were calculated from the mercury intrusion data ${ }^{4}$. Consequently, the specific surface area determined by the BET method also decreases from $422 \mathrm{~m}^{2} / \mathrm{g}$ for the $\gamma-\mathrm{Al}_{2} \mathrm{O}_{3}$ monolith to $11 \mathrm{~m}^{2} / \mathrm{g}$ for the $\alpha-\mathrm{Al}_{2} \mathrm{O}_{3}$ monolith. For porous alumina, these porosity values are already among the highest ones achieved to date [12]. Ongoing studies concentrate on the optimization of the procedure with special focus on the gel

\footnotetext{
${ }^{2}$ XRD patterns are plotted in Fig. S1

3 Experimental details on both the synthesis and characterization methods can be found in the ESI.

${ }^{4}$ The corresponding mercury intrusion dataset is plotted in Fig. S2.
}

formation as a key point of the synthesis. Moreover, variation of the synthesis parameters as well as the introduction of additives might not only alter but also further increase the porosity of the described alumina monoliths.

In conclusion, this communication presents an important step forward in the sol-gel synthesis of porous alumina monoliths. As described before by other groups, an aluminum salt and an aluminum alkoxide are employed as two homonuclear precursors $[2,10,11]$. In our approach, this was done without an aqueous phase for the first time, using ethanol and 2-propanol as a polar and acidic medium. The use of a carcinogenic epoxide to initiate hydrolysis is unnecessary, as both precursors readily hydrolyze each other. Moreover, mechanically stable gels can be reliably produced using an autoclave for the gel formation process. As the result of a meticulous solvent exchange and drying procedure, crack-free xerogels are obtained. These are convertible into different alumina modifications by an adequate calcination step. The omission of the carcinogenic epoxide as well as the improved procedure to fabricate porous alumina monoliths represent significant advancements in the sol-gel synthesis of alumina.

Funding Open Access funding enabled and organized by Projekt DEAL.

\section{Compliance with ethical standards}

Conflict of interest The authors declare no competing interests.

Publisher's note Springer Nature remains neutral with regard to jurisdictional claims in published maps and institutional affiliations.

Open Access This article is licensed under a Creative Commons Attribution 4.0 International License, which permits use, sharing, adaptation, distribution and reproduction in any medium or format, as long as you give appropriate credit to the original author(s) and the source, provide a link to the Creative Commons license, and indicate if changes were made. The images or other third party material in this article are included in the article's Creative Commons license, unless indicated otherwise in a credit line to the material. If material is not included in the article's Creative Commons license and your intended use is not permitted by statutory regulation or exceeds the permitted use, you will need to obtain permission directly from the copyright holder. To view a copy of this license, visit http://creativecommons. org/licenses/by/4.0/.

\section{References}

1. Yoldas BE (1975) Alumina Sol Preparation from Alkoxides Am Cer Soc Bull 54:289; Yoldas BE (1975) Alumina gels that form porous transparent $\mathrm{Al}_{2} \mathrm{O}_{3} \mathrm{~J}$ Mater Sci 10:1856-1860

2. Clark DE, Dalzell WJ, Adams BL (1989) Inorganic salts as peptizing agents in the preparation of metal oxide sol-gel compositions, US Patent 4,801,399

3. Gash AE, Tillotson TM, Satcher JH, Poco JF, Hrubesh LW, Simpson RL (2001) Chem Mater 13:999-1007. https://doi.org/10. $1021 / \mathrm{cm} 0007611$ 
4. Baumann TF, Gash AE, Chinn SC, Sawvel AM, Maxwell RS, Satcher JH (2005) Chem Mater 17:395-401. https://doi.org/10. $1021 / \mathrm{cm} 048800 \mathrm{~m}$

5. Tokudome Y, Fujita K, Nakanishi K, Miura K, Hirao K (2007) Chem Mater 19:3393-3398. https://doi.org/10.1021/cm063051p

6. Tokudome Y, Nakanishi K, Kanamori K, Fujita K, Akamatsu H, Hanada T (2009) J Colloid Interfac Sci 338:506-513. https://doi. org/10.1016/j.jcis.2009.06.042

7. Tokudome Y, Nakanishi K, Kanamori K, Hanada T (2010) J Colloid Interfac Sci 352:303-308. https://doi.org/10.1016/j.jcis. 2010.08.041

8. Carstens S, Enke D (2019) J Eur Cer Soc 39:2493-2502. https:// doi.org/10.1016/j.jeurceramsoc.2019.01.043
9. Carstens S, Splith C, Enke D (2019) Sci Rep 9:19982. https://doi. org/10.1038/s41598-019-56294-1

10. Dressler M, Nofz M, Malz F, Pauli J, Jäger C, Reinsch S, Scholz G (2007) J Solid State Chem 180:2409-2419. https://doi.org/10. 1016/j.jssc.2007.06.018

11. Nofz M, Pauli J, Dressler M, Jäger C, Altenburg W (2006) J SolGel Sci Technol 38:25-35. https://doi.org/10.1007/s10971-0055546-0

12. Carstens S, Meyer R, Enke D (2020) Materials 13:1787. https:// doi.org/10.3390/ma13071787 